DOI 10.15593/2224-9354/2017.2.19

УДК 378.091 .8

О.А. Тимофеева, Е.Н. Покатилова, Д.В. Сокерин

\title{
ИСПОЛЬЗОВАНИЕ ЗАРУБЕЖНОГО ОПЫТА ПРОВЕДЕНИЯ УНИВЕРСИТЕТСКИХ ФЕСТИВАЛЕЙ ПРИ ОРГАНИЗАЦИИ СОБЫТИЙНЫХ МЕРОПРИЯТИЙ В РОССИЙСКИХ ВУЗАХ НА ПРИМЕРЕ СТУДЕНЧЕСКОГО ФЕСТИВАЛЯ «КАМПУС ФЕСТ»
}

\begin{abstract}
Одним из важнейших направлений маркетинговой деятельности любой организации, существующей в конкурентной среде, в том числе и образовательных учреждений, является выстраивание коммуникаций с целевой аудиторией. Качественно выстроенные коммуникации позволяют эффективно рассказать потребителю о деятельности и продуктах компании, создать или укрепить в сознании потребителя правильное восприятие бренда. Для продвижения учебного заведения эффективным средством является использование событийного маркетинга. Авторами проанализированы самые популярные в последние годы события в иностранных университетах. С целью изучения зарубежного опыта проведения событийного маркетинга в учебных заведениях были проведено исследование, которое включало в себя такие мероприятия, как контентанализ крупных студенческих фестивалей, серия глубинных интервью и онлайн-опрос. Участниками глубинных интервью стали пермские студенты, имеющие опыт обучения за рубежом. В рамках проведенного исследования была изучена проблематика применения инструментария событийного маркетинга в целях продвижения образовательных услуг учебными заведениями.

Был рассмотрен зарубежный опыт проведения университетских фестивалей ведущими университетами мира. При помощи проведения глубинного интервью было выявлено, что event marketing активно применяется любыми учебными заведениями для продвижения собственных услуг и признается эффективным каналом коммуникации с потребителями - студентами и абитуриентами. Авторы считают, что различные мероприятия, проводимые в университете, - это способ продвижения учебных заведений в условиях растущей конкуренции за потребителя. Таким образом, сформулированы предложения по совершенствованию событийных мероприятий в российских университетах на примере студенческого фестиваля «Кампус Фест», который проводится в Пермском государственном национальном исследовательском университете.

Ключевые слова: event marketing, событийный маркетинг, университетские фестивали, event, маркетинговые коммуникации, продвижение, маркетинговые исследования.
\end{abstract}

Одной из основных целей вуза является выстраивание коммуникаций с целевой аудиторией. Следовательно, для любого вуза важно: увеличение объемов платного образования, узнаваемость торговой марки вуза, усиление партнерских отношений с внутренней аудиторией, увеличение ее лояльности, расширение дополнительного и бизнес-образования, вывод на рынок новых

(C) Тимофеева О.А., Покатилова Е.Н., Сокерин Д.В., 2017

Тимофеева Ольга Абдулловна - доцент кафедры маркетинга ФГБОУ ВО «Пермский государственный национальный исследовательский университет», e-mail: marketing.psu@yandex.ru.

Покатилова Елена Николаевна - студент экономического фракультета ФГБОУ ВО «Пермский государственный национальный исследовательский университет», e-mail: marketing.psu@yandex.ru.

Сокерин Дмитрий Вячеславович - студент экономического факультета ФГБОУ ВО «Пермский государственный национальный исследовательский университет», e-mail: marketing.psu@yandex.ru. 
предложений (специальностей), усиление «академического пиара», укрепление и расширение международного сотрудничества и др. [1].

Особое место в продвижении учебных заведений и осуществляемых ими образовательных услуг занимает event marketing. Событийный маркетинг (event marketing) - это специально разработанный комплекс маркетинговых мероприятий для продвижения интересов компании или организации с помощью какого-либо запоминающегося события, уже известного широкой публике либо созданного специально под целевые задачи компании [2]. Такими событиями могут являться, в частности, выставки, конференции, городские праздники, фестивали, концерты. Подобные мероприятия встречают положительный отклик со стороны участников и имеют ощутимое воздействие на целевую аудиторию, в первую очередь, благодаря непосредственному участию потенциальных и реальных потребителей в событии, ведь люди намного лучше запоминают то, что испытали сами. «Я слышу и забываю. Я вижу и помню. Я испытываю и понимаю», - эти слова мыслителя и философа Конфуция как нельзя лучше описывают эффект, ожидаемый от событийного маркетинга.

В условиях всевозрастающей конкуренции образовательные учреждения и, в первую очередь, ведущие университеты мира активно используют возможности событийного маркетинга [3, с. 35]. Подтверждением этого служит обширный перечень университетских праздников и фестивалей, которые появились и стали традиционными во многих университетах Европы и мира: фестивали музыки и театра, юбилейные торжества, чтения стихов и хоры в честь выборов ректора, юмористические празднества и т.д.

Рассмотрим некоторые из самых заметных в последние годы событий в иностранных университетах (таблица).

Мероприятия событийного маркетинга в университетах мира

\begin{tabular}{|c|c|c|}
\hline $\begin{array}{c}\text { № } \\
\Pi / \Pi\end{array}$ & Мероприятие & Формат и содержание \\
\hline 1 & $\begin{array}{l}\text { Международная } \\
\text { студенческая неделя } \\
\text { в Ильменау (ISWI), } \\
\text { Германия }\end{array}$ & $\begin{array}{l}\text { В течение недели участники обсуждают разные темы, слуша- } \\
\text { ют лекции и посещают всевозможные культурные события, } \\
\text { например, музыкальные концерты или просмотры фильмов. } \\
\text { Проводится ТВ (интернет) трансляция. ISWI - самый крупный } \\
\text { студенческий фестиваль в Германии [4] }\end{array}$ \\
\hline 2 & $\begin{array}{l}\text { Cambridge } \\
\text { Festival of Ideas, } \\
\text { Великобритания }\end{array}$ & $\begin{array}{l}\text { В течение } 14 \text { дней в Кембридже проходят сотни бесплатных } \\
\text { мероприятий с участием исследователей из Кембриджского } \\
\text { университета, местных общественных деятелей и известных } \\
\text { гостей фестиваля. Сambridge Festival of Ideas - это праздник } \\
\text { искусства, гуманитарных и социальных наук, демонстрирует } \\
\text { различные сочетания спектаклей, фильмов, выставок и других } \\
\text { творческих проявлений, а также исследования темы власти. } \\
\text { Фестиваль включает в себя дискуссии, семинары, переговоры, } \\
\text { выставки. В } 2016 \text { году фестиваль проводится в девятый раз. } \\
\text { Для тех, кто пропустил фестиваль, есть удобная опция: доступ } \\
\text { к аудиозаписям со всех лекций и мероприятий [5] }\end{array}$ \\
\hline
\end{tabular}

PNRPU Sociology and Economics Bulletin. 2017. No. 2 
Окончание таблицы

\begin{tabular}{|c|c|c|}
\hline $\begin{array}{c}\text { № } \\
\Pi / \Pi\end{array}$ & Мероприятие & Формат и содержание \\
\hline 3 & $\begin{array}{l}\text { Международный } \\
\text { студенческий } \\
\text { фестиваль } \\
\text { в Тронхейме (ISFIT), } \\
\text { Норвегия }\end{array}$ & $\begin{array}{l}\text { Участники фестиваля объединяются в группы для совме- } \\
\text { стной работы и посещают различные семинары, на кото- } \\
\text { рых могут обмениваться своими идеями, мыслями и опы- } \\
\text { том. Темы ежегодно меняются, но они всегда имеют соци- } \\
\text { альный и политический уклон. Фестиваль посещали } \\
\text { многие известные люди: нобелевские лауреаты, политиче- } \\
\text { ские и культурные деятели и даже Далай Лама [6] }\end{array}$ \\
\hline 4 & $\begin{array}{l}\text { Студенческая } \\
\text { конференция } \\
\text { в Мариборе (SCiM), } \\
\text { Словения }\end{array}$ & $\begin{array}{l}\text { Фестиваль длится } 10 \text { дней. Участники фестиваля обсуж- } \\
\text { дают темы, связанные с политикой, будущим европейских } \\
\text { государств, развитием высшего образования, проблемами } \\
\text { трудоустройства и безработицы. Первая конференция бы- } \\
\text { ла проведена в } 1996 \text { году. Ежегодно SCiM посещают пред- } \\
\text { ставители более чем } 15 \text { стран, в основном европейских [7] }\end{array}$ \\
\hline 5 & $\begin{array}{l}\text { Университетский } \\
\text { фестиваль } \\
\text { (Daedongjae) } \\
\text { на базе Yonsei } \\
\text { University, Корея }\end{array}$ & $\begin{array}{l}\text { Ежегодно, в конце мая кампус Yonsei University превращает- } \\
\text { ся в фестивальную площадку - с многочисленными магази- } \\
\text { нами, студенческими клубами, продавая все: от коктейлей до } \\
\text { уличной еды и футболок. После захода солнца участники } \\
\text { собираются на сцене, сидя в палатках, на картонных короб- } \\
\text { ках.Фестиваль в университете Йонсей продолжается в тече- } \\
\text { ние } 3 \text { дней и заканчивается AKARAKA - концертом, кото- } \\
\text { рый демонстрирует дух университета. Праздник является для } \\
\text { студентов способом отпраздновать завершение сессий, } \\
\text { а также отдохнуть перед выпускными экзаменами [8] }\end{array}$ \\
\hline 6 & $\begin{array}{l}\text { Международная } \\
\text { студенческая неделя } \\
\text { (ISWIb), Сербия }\end{array}$ & $\begin{array}{l}\text { ISWIb - студенческий фестиваль, который ежегодно про- } \\
\text { водится в столице Сербии. Участники студенческой неде- } \\
\text { ли объединяются для совместной работы на различных } \\
\text { мастер-классах, каждый из которых представляет важную } \\
\text { сферу общественной жизни [9] }\end{array}$ \\
\hline 7 & $\begin{array}{l}\text { May Festival } \\
\text { University } \\
\text { of Aberdeen, } \\
\text { Шотландия }\end{array}$ & $\begin{array}{l}\text { Трехдневный фестиваль, проводится в Университете } \\
\text { Абердина в мае. В центре внимания участников фестиваля } \\
\text { последние научные открытия, спорт, литература, окру- } \\
\text { жающая среда, музыка, архитектура и дизайн, история, } \\
\text { общественное питание, путешествия [10] }\end{array}$ \\
\hline
\end{tabular}

Авторами был проведен контент-анализ крупных студенческих фестивалей, проводимых зарубежными университетами, в ходе которого были выделены основные тенденции подобных мероприятий [11]. К ним можно отнести большую продолжительность фестивалей (3-14 дней); акцент на научной составляющей; экономическую или политическую направленность дискуссий. Данные выводы будут учтены при формулировке основных выводов исследования. При этом следует иметь в виду, что прямое сравнение фестивалей не является корректным, так как каждый event индивидуален, имеет собственные цели и соответствующий целям формат.

Учитывая растущую конкуренцию за потребителя, как внутри страны, так и между российскими и зарубежными университетами, внимание событийному 
маркетингу в последние годы начали уделять и российские вузы. Место подобным мероприятиям нашлось и на территории Пермского края. Так, в первом на Урале Пермском государственном национальном исследовательском университете (ПГНИУ) за последние 3-5 лет было инициировано и ежегодно проводится сразу несколько событийных мероприятий, таких как «Кампус Фест», «Ночь в университете», «Пермский конгресс ученых-экономистов», «Economics Day», «Perm Winter School». В данной статье особое внимание будет уделено первому из перечисленных событийных мероприятий.

«Кампус Фест» - фестиваль под открытым небом, который проводится в Перми с 2014 года. Инициатором и основным организатором фестиваля является экономический факультет ПГНИУ. Согласно данным, опубликованным на официальном сайте ПГНИУ, в 2015 году за один день фестиваль посетило более 6000 человек [12]. Программа мероприятия включала в себя концерты, мастер-классы, выставки, лектории, дискуссионные площадки. Самыми яркими акцентами фестиваля стала музыкальная площадка, организованная партнером фестиваля - радиостанцией «Европа Плюс Пермь»; масштабный турнир по стрит-баскетболу, который открыла олимпийская чемпионка Светлана Антипова; школьный квест и танцевальный марафон. Отметим, что профессионализм организаторов фестиваля «Кампус Фест» был отмечен в 2015 году серебряной наградой международного конкурса Global Event Awards за достижения в области событийного маркетинга [13].

Мероприятие широко освещалось в региональных средствах массовой информации. Общая тональность публикаций положительная. Для анализа впечатлений непосредственных участников фестиваля был проведен контентанализ социальных сетей: паблика фестиваля, ленты новостей, отзывов участников, найденных по соответствующим хэштегам, типа \#КампусФест в социальных сетях ВКонтакте и Instagram. Тональность высказываний участников фестиваля в целом соответствует положительной тональности публикаций в прессе, но носит ярко выраженный эмоциональный характер.

Несмотря на успешный опыт проведения университетом фестиваля «Кампус Фест» и других events, очевидным представляется тот факт, что в сравнении с ведущими зарубежными университетами ПГНИУ является новичком в сфере событийного маркетинга. Учитывая это, а также очевидное стремление университета использовать event marketing в качестве эффективного инструмента для продвижения вуза и привлечения абитуриентов, авторы, представляющие кафедру маркетинга ПГНИУ, провели комплексное исследование. Целью исследования стал сбор уникальной информации о студенческих фестивалях, проводимых в зарубежных университетах, и выработка на основе полученной информации рекомендаций по совершенствованию университетских событийных мероприятий на примере студенческого фестиваля «Кампус Фест». 
Исследование включало в себя контент-анализ успешного опыта зарубежных вузов, представленный авторами в начале статьи, а также серию глубинных интервью и онлайн-опрос.

Участниками глубинных интервью стали пермские студенты, имеющие опыт обучения за рубежом. Первый респондент - студент 1-го курса магистратуры экономического факультета ПГНИУ - получил базовое образование на родине, в Университете Алжира 2. В ходе интервью выяснилось, что респондент не только знаком с университетскими мероприятиями, проводимыми в Алжире, но и принимал активное участие в организации проводимого ежегодно фестиваля «Berber Spring». Данный фестиваль проводится в апреле в течение 4 дней. Основная тема - политика, традиции и культура народов берберов. Место проведения - территория университетского кампуса. Каждый из фестивальных дней имеет собственную программу, включающую в себя различные развлекательные и образовательные мероприятия: выставки национальной одежды и украшений, лектории и конференция об истории и культуре народа, танцы и концерт. Важным элементом программы являлись дебаты, на которых могли выступить все желающие и озвучить свои мнения по тому или иному вопросу. В качестве организаторов фестиваля выступали студенты, администрация университета, журналисты, а в качестве участников - студенты, профессора, население города. Кроме того, на мероприятие приглашаются гости, широко известные в Алжире - артисты, журналисты, политики, адвокаты. Однозначно ответить на вопрос о количестве пришедших людей респондент не смог, но он подчеркнул, что данный фестиваль очень популярен.

На вопрос о том, влияют ли университетские мероприятия на решения абитуриентов, выбирающих учебное заведение, респондент ответил утвердительно. По его мнению, подобные мероприятия помогают абитуриентам узнать о жизни университета, адаптироваться к новой обстановке и завязать новые знакомства. Интересно, что на вопрос о том, какого рода мероприятия в Перми были бы интересны респонденту, он, вопреки ожиданиям исследователей, назвал не развлекательные или спортивные events, а отметил, что его заинтересовали бы мероприятия, связанные с аутентичностью Пермского края.

Второй респондент - студент из Китая, окончивший Anhui University и в настоящее время обучающийся в Перми. В ходе интервью респондент подробно рассказал о различных фестивалях, лекториях и спортивных мероприятиях, которые проводятся в Аньхойском университете. Особый акцент респондент сделал на спортивных events. Так, в апреле в университете проходит Спартакиада по различным атлетическим видам спорта - крупное университетское мероприятие, в котором ежегодно принимают участие более 1000 студентов-спортсменов.

На вопрос, знаком ли респондент с пермскими фестивалями под открытым небом, он ответил, что знает только «Белые ночи»- масштабный 
краевой фестиваль, проводившийся в Перми в 2012-2014 годах, который произвел на интервьюируемого неизгладимое впечатление. По мнению респондента, при организации пермских фестивалей было бы целесообразно улучшить работу волонтеров с иностранцами. Говоря о влиянии университетских мероприятий на формирование положительного имиджа университета и увеличение количества поступающих в учебное заведение, респондент также дал однозначно утвердительный ответ. По его словам, подобные мероприятия ярко иллюстрируют студенческую жизнь и формируют мнение абитуриента об университете.

Третьим респондентом стала российская студентка, обучающаяся по программе студенческого обмена в Niagara College (Онтарио, Канада). Как она говорит, колледж активно участвует в организации многих мероприятий и фестивалей, из которых наиболее ярким является фестиваль вина под открытым небом «Ісе Wine». Данный фестиваль проводится в Онтарио в январе, его организуют городские власти, a Niagara College оказывает спонсорскую и волонтерскую поддержку. В рамках данного фестиваля проводятся шествия по городу, сооружаются ледяные скульптуры, проводятся дегустации различных блюд и вин. Выбор тематики фестиваля обусловлен историей города: Онтарио издавна славится своим виноградом и винами. По утверждению респондента, несмотря на специфическую тематику фестиваля, участие колледжа в его организации способствует повышению мотивации студентов на обучение в этом колледже; нацеливает их на участие в различных благотворительных мероприятиях; расширяет мировоззрение студентов; дает новый опыт и знакомит с потенциальными работодателями.

Отметим, что полученная от данного респондента информация во многом совпала с рекомендациями первого респондента, который говорил о необходимости акцентирования содержания мероприятия на аутентичных особенностях территории, ее исторической и культурной уникальности.

Таким образом, проведенные авторами статьи глубинные интервью продемонстрировали, что event marketing активно применяется любыми учебными заведениями для продвижения собственных услуг и признается эффективным каналом коммуникации с потребителями - студентами и абитуриентами. Также в ходе интервью, взятых у студентов из Алжира, Китая и Канады, респондентами было отмечено, что в каждой из этих стран мероприятия обладают своими особенностями: в формате проведения, направленности и тематике. При этом каждый из респондентов подчеркивал, что подобные фестивали оказывают положительное влияние на выбор абитуриентами учебных заведений, на их адаптацию к университетской жизни и, в целом, на их лояльность тому или иному университету.

На основе проведенного исследования и анализа вторичной информации, включающей в себя обзор зарубежных университетских фестивалей, ав- 
торы выдвигают гипотезу: внесение нескольких, представленных далее, изменений в организацию и проведение фестиваля «Кампус Фест» способно существенно повысить его привлекательность и эффективность.

Во-первых, предлагается увеличить длительность фестиваля «Кампус Фест» с одного до нескольких дней, что позволит существенно расширить программу мероприятий, привлечь дополнительных участников, увеличить количество откликов в социальных сетях и средствах массовой информации.

Во-вторых, с учетом роста потребления видеоконтента как одного из наиболее заметных трендов последних лет предлагается организовать интернет-трансляцию лектория, мастер-классов и иных образовательных мероприятий «Кампус Феста». Данный шаг способен положительно повлиять на расширение аудитории фестиваля.

Следующее предложение касается организации на фестивале различных диспутов в формате «открытого микрофона», позволяющего всем желающим выступить или подискутировать на заранее обозначенные (или же свободные) темы, что повысит вовлеченность участников в происходящее.

Предлагается также рассмотреть возможность расширения программы «Кампус Феста» за счет мероприятий, связанных со спецификой региональной экономики и бизнеса - темами, наиболее популярными на сегодняшний день среди существенной части целевой аудитории фестиваля - абитуриентов и студентов экономического факультета - будущих управленцев и владельцев бизнеса.

Привлечение к участию в «Кампус Фесте» представителей не только ПГНИУ, но и других вузов, как в роли спикеров, так и участников, - еще одно предложение, позволяющее, по мнению авторов, увеличить аудиторию фестиваля, повысить его узнаваемость и престиж.

Дополнительно предлагается обратить внимание на отмеченный в ходе одного из глубинных интервью факт, что при проведении любого мероприятия существенной является ситуация непонимания происходящего со стороны людей, не являющихся носителями языка, на котором проводится мероприятие, и не знающих местных традиций. Поскольку в ПГНИУ обучается большое количество иностранных студентов, данный факт необходимо учитывать при организации «Кампус Феста» и других событийных мероприятий, в том числе при организации работы волонтеров и разработке навигационных и рекламных материалов.

Заключительной новацией, предлагаемой организаторам фестиваля «Кампус Фест» авторами статьи, является предложение организовывать фестиваль несколько раз в год, в том числе зимой. Суровая, но красивая зима на Урале позволит сделать зимний фестиваль уникальным, соединяющим в своей программе как аутентичные уральские традиции, такие как катание с гор, взятие снежного городка, чаепитие с блинами у самовара, танцы в валенках, сжигание Масленицы, так и современные: квесты, воркшопы, мастер-классы, лектории, спортивные, интеллектуальные и музыкальные батлы. Поскольку 
зима - самое непопулярное время для фестивалей, проведение «Кампус Феста» зимой могло бы привлечь совершенно новую аудиторию фестиваля школьников из различных российских регионов, которые приехав в фестиваль во время зимних каникул, могут стать в будущем лояльными абитуриентами ПГНИУ. Кроме того, аутентичный зимний «Кампус Фест» мог бы привлечь зарубежных туристов, а также стать информационным поводом не только для региональных, но и федеральных средств массовой информации.

Для подтверждения или опровержения выдвинутой гипотезы авторами было проведено маркетинговое исследование в формате онлайн-опроса. Выборка, в которую вошли 102 респондента, была сформирована методом простого случайного отбора из совокупности студентов, сотрудников и выпускников ПГНИУ, а также абитуриентов - пользователей социальной сети ВКонтакте. Для оценки отношения респондентов к предложениям авторов в анкете была использована дифференцированная шкала Лайкерта, представляющая собой шкалу с пятью делениями, где 1 означает «совершенно не согласен», а 5 - «полностью согласен» [14, с. 342].

Результаты опроса показали, что шесть из семи сформулированных авторами предложений вызвали у респондентов преимущественно положительный отклик. В частности, 63,8 \% участников онлайн-опроса положительно отнеслись к предложению делать акцент на специфике экономики в Пермском крае в деловой программе «Кампус Феста» (рис. 1).

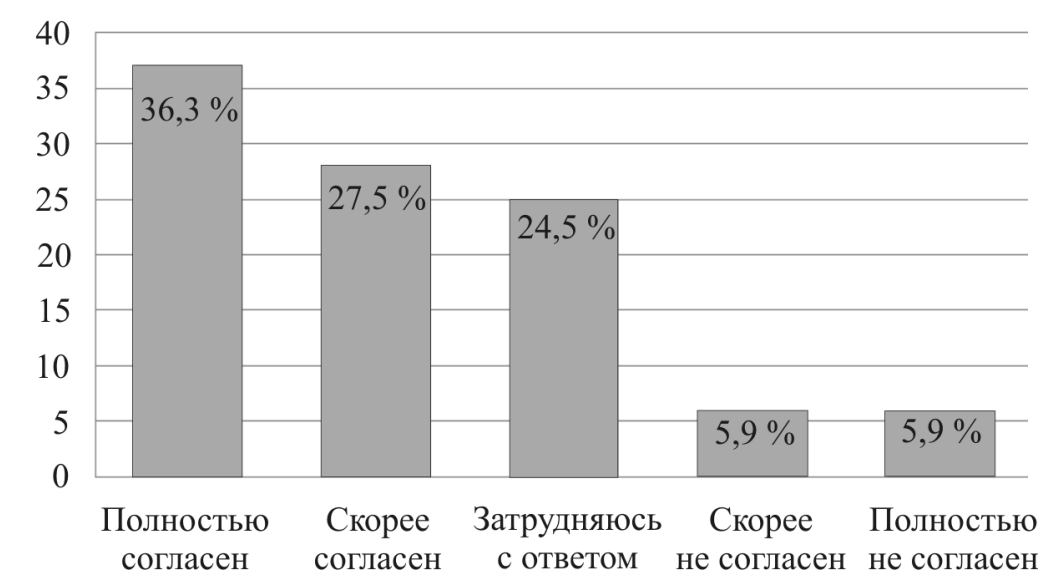

Рис. 1. Отношение респондентов к предложению о расширении деловой программы фестиваля

Положительно респонденты оценили предложение по привлечению к участию в фестивале других учебных заведений (70,6 \% - положительно; $13,7 \%$ - отрицательно).

Наименее однозначно респондентами было воспринято предложение о проведении фестиваля «Кампус Фест» зимой (рис. 2). 


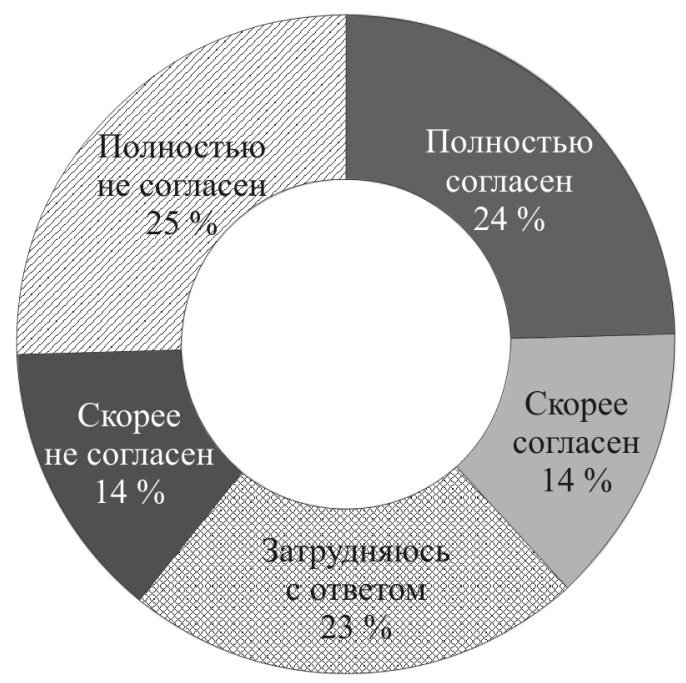

Рис. 2. Отношение респондентов к вопросу о проведении фестиваля зимой

Несмотря на существенный разброс мнений респондентов по данному вопросу, авторы настаивают на своем предложении и единодушно считают, что зимние фестивали будут позитивно восприняты участниками, особенно целевой аудиторией - студенчеством и школьниками, как представителями наиболее новаторского сегмента потребителей. Кроме того, зимний университетский фестиваль будет способствовать формированию имиджа ПГНИУ современного, открытого всему новому, креативного университета.

В ходе исследования респондентам был задан открытый вопрос о том, есть ли у них собственные предложения по организации фестиваля «Кампус Фест». На данный вопрос содержательно ответили 17 \% респондентов. Резюмируя полученные ответы, можно сделать вывод, что участники опроса считают важным расширение точек продажи сувенирной атрибутики фестиваля, еды и напитков; увеличение количества площадок, на которых участники фестиваля могут проявить себя; совместные активности с некоммерческими и волонтерскими организациями; проведение фестиваля в выходной день; привлечение известных хэдлайнеров.

Таким образом, в рамках проведенного исследования была изучена проблематика применения инструментария событийного маркетинга в целях продвижения образовательных услуг учебными заведениями; был рассмотрен зарубежный опыт проведения университетских фестивалей ведущими университетами мира. Для верификации сформулированных гипотез был проведен онлайн-опрос среди абитуриентов, студентов, выпускников и сотрудников ПГНИУ. 
Резюмируя итоги комплексного исследования, авторы полагают, что еще более привлекательным для целевой аудитории и эффективным способны сделать фестиваль «Кампус Фест» следующие изменения и дополнения:

1. Использование опыта зарубежных университетов в проведении фестивалей.

2. Увеличение длительности фестиваля.

3. Проведение фестиваля в наиболее удобное для целевой аудитории время - в выходные дни.

4. Организация интернет-трансляции лектория, мастер-классов, дебатов.

5. Увеличение вовлеченности участников за счет интерактива: игр, дебатов, квестов.

6. Фокусирование контента деловых площадок фестиваля на специфике экономики и бизнеса Пермского края.

7. Привлечение на фестиваль в качестве хэдлайнеров известных ученых, политиков, общественных деятелей, музыкальных исполнителей и т.д.

8. Использование комаркетинга с различными коммерческими и некоммерческими структурами.

9. Расширение ассортимента сопутствующих товаров, предлагаемых участникам фестиваля: еда, напитки, сувенирная продукция с университетской атрибутикой.

10. Повышение аутентичности фестиваля, использование в контенте фестиваля уникальных культурных и исторических особенностей Пермского края.

11. Проведение зимнего фестиваля «Кампус Фест».

Безусловно, некоторые из представленных предложений требуют дополнительного изучения, расчета экономической и маркетинговой целесообразности и могут стать основой для дальнейших исследований. Но в целом, по мнению авторов, данные предложения способны усилить контент университетского фестиваля «Кампус Фест», привлечь абитуриентов, т.е. основных потребителей услуги вуза, стать дополнительным аргументом при выборе высшего учебного заведения и укрепить имидж ПГНИУ как открытого новациям, креативного и современного университета [15].

\section{Список литературы}

1. Event-markrting. Moscow Business School. - URL: https://media. professionali.ru/processor/wiki/original/2014/04/24/event-marketing.pdf (accessed 20 Juny 2016).

2. Гусев И.Б., Леденцова Е.А. Продвижение маркетинговой деятельности в вузах // Маркетинг МВА. Маркетинговое управление предприятием. 2014. - Вып. 2. - С. 64-73.

3. Касимова Э.Р., Кузнецова Е.В. Event маркетинг высшего учебного заведения // Бизнес. Образование. Право. Вестник Волгоградского института бизнеса. - 2015. - № 4. - С. 345-350. 
4. University of Aberdeen May Festival. - URL: https://wwwmayfestival/ (accessed 20 Juny 2016).

5. SCIM - Student Conference in Maribors. - URL: http://www.scim.si/ (accessed 20 Juny 2016).

6. University Festivals in Korea. - URL: http://www.talktomeinkorean.com/ blog/unifestivals/ (accessed 20 Juny 2016).

7. Festival of Ideas, URL: http://www.festivalofideas.cam.ac.uk (accessed 20 Juny 2016).

8. ISFiT - Trade Your Ideas. - URL: https://www.isfit.org (accessed 20 Juny 2016).

9. ISWI 2015 - International Student Week in Ilmenau. - URL: http://2015. iswi.org/(accessed 20 Juny 2016).

10. ISWiB 2016. - URL: http://www.iswib.org/ (accessed 20 Juny 2016).

11. Международные студенческие фестивали [Электронный ресурс]. URL: http://tmstudent.ru/article/mezhdunarodnye-studencheskie-festivali (дата обращения: 20.06.2016).

12. Мечты бизнесменов, квест, музыка и гигантский пряник - в Перми прошел «Кампус Фест» [Электронный ресурc]. - URL: http://www.psu.ru/ news-archive/year-2015/mechty-biznesmenov-kvest-muzyka-i-gigantskij-pryanikv-permi-proshel-kampus-fest (дата обращения: 20.06.2016).

13. «Кампус Фест» признан одним из лучших массовых мероприятий в CHГ [Электронный pecypc]. - URL: http://econom.psu.ru/news/news inn.php?id=1828\&sphrase_id=7022 (дата обращения: 20.06.2016).

14. Малхотра Н. Маркетинговые исследования: пер. с англ. - М.: Вильямс, 2008. - 1200 с.

15. Гладких Я.Н., Чепурных Е.Э. Роль коммуникационной составляющей в инфраструктуре современного вуза (на примере ФГБОУ ВО «Пермский государственный национальный исследовательский университет») // Маркетинг MBA. Маркетинговое управление предприятием. - 2014. - Т. 5. - С. 63-73.

\section{References}

1. Event-marketing. Moscow business school. Available at: https://media. professionali.ru/processor/wiki/original/2014/04/24/event-marketing.pdf (accessed 20 June 2016).

2. Gusev I.B., Ledentsova E.A. Prodvizhenie marketingovoi deiatel'nosti v vuzakh [Promotion of marketing activities at universities]. Marketing MVA. Marketingovoe upravlenie predpriiatiem, 2014, issue 2, pp. 64-73.

3. Kasimova E.R., Kuznetsova E.V. Event marketing vysshego uchebnogo zavedeniia [Event marketing of a higher education institution]. Biznes. Obrazovanie. Pravo. Vestnik Volgogradskogo instituta biznesa, 2015, no. 4, pp. 345-350. 
4. University of Aberdeen. May festival. Available at: https://www.abdn.ac.uk/ mayfestival/ (accessed 20 June 2016).

5. SCIM - Student Conference in Maribors. Available at: http://www.scim.si/ (accessed 20 June 2016).

6. University Festivals in Korea. Available at: http://www.talktomeinkorean.com/blog/unifestivals/ (accessed 20 June 2016).

7. Festival of Ideas. Available at: http://www.festivalofideas.cam.ac.uk/ (accessed 20 June 2016).

8. ISFiT - Trade Your Ideas. Available at: https://www.isfit.org/ (accessed 20 June 2016).

9. ISWI 2015 - International Student Week in Ilmenau. Available at: http://2015.iswi.org/ (accessed 20 June 2016).

10. ISWiB 2016. Available at: http://www.iswib.org/ (accessed 20 June 2016).

11. Mezhdunarodnye studencheskie festivali [International student festivals]. Available at: http://tmstudent.ru/article/mezhdunarodnye-studencheskie-festivali (accessed 20 June 2016).

12. Mechty biznesmenov, kvest, muzyka i gigantskii prianik - v Permi proshel "Kampus Fest" [Dreams of businessmen, quest, music and a giant gingerbread - Perm holds "Campus Fest"]. Available at: http://www.psu.ru/newsarchive/year-2015/mechty-biznesmenov-kvest-muzyka-i-gigantskij-pryanik-vpermi-proshel-kampus-fest (accessed 20 June 2016).

13. "Kampus Fest" priznan odnim iz luchshikh massovykh meropriiatii v SNG ["Campus Fest" is considered one of the best mass events in the CIS]. Available at: http://econom.psu.ru/news/news_inn.php?id=1828\&sphrase_id=7022 (accessed 20 June 2016).

14. Malhotra N.K. Marketing research. An applied operation. 4th ed. Upper Saddle River Publ., 2004 [Russ. ed.: Malkhotra N. Marketingovye issledovaniia. Moscow, Vil'iams Publ., 2008, 1200 p.].

15. Gladkikh Ia.N., Chepurnykh E.E. Rol' kommunikatsionnoi sostavliaiushchei v infrastrukture sovremennogo vuza (na primere FGBOU VO "Permskii gosudarstvennyi natsional'nyi issledovatel'skii universitet") [The role of communication component in the infrastructure of a modern university (the case study of Federal State Budgetary Educational Institution of Higher Education "Perm State National Research University"]. Marketing MVA. Marketingovoe upravlenie predpriiatiem, 2014, vol. 5, pp. 63-73.

Оригинальность статьи - $95 \%$

Получено 29.12.2016

PNRPU Sociology and Economics Bulletin. 2017. No. 2 


\author{
O.A. Timofeeva, E.N. Pokatilova, D.V. Sokerin
}

\title{
USING FOREIGN EXPERIENCE OF UNIVERSITY FESTIVALS ORGANIZATION IN HOLDING UNIVERSITY EVENTS IN RUSSIA (THE CASE STUDY OF “CAMPUS FEST” STUDENT FESTIVAL)
}

Communication with the target audience is seen as one of the most important branches of marketing activities of any organization that functions within a competitive environment. Thus, the effectively organized communication makes it possible to inform the consumer about company's business as well as its products and to create certain perception of the brand. In order to effectively promote an educational establishment, event marketing can be applied. The authors of the paper analyze the most prominent recent events in foreign universities with the purpose of studying foreign principles of event marketing. The research includes a content analysis of major student festivals, with a series of in-depth interviews and online polling. The respondents of in-depth interviews represent Perm students who have had experience of studying abroad. The research also studies the issues of using event marketing tools for the promotion of educational services by a university. In-depth interviews results revealed that event marketing is actively used by any educational establishment in order to promote their services. It appears to be an effective communication channel to inform future consumers - applicants and students. The authors claim that the events held by universities can help promote their educational services under the conditions of increased competition. The article formulates suggestions for the improvement of event marketing in Russian universities by the example of "Campus Fest" student festival held in Perm Krai by Perm State National Research University.

Keywords: event marketing, university festivals, event, marketing communications, promotion, marketing research.

Olga A. Timofeeva - Associate Professor, Dept. of Marketing, Perm State National Research University, e-mail: marketing.psu@yandex.ru.

Elena N. Pokatilova - Undergraduate Student of Management, Perm State National Research University, e-mail: marketing.psu@yandex.ru.

Dmitry V. Sokerin - Undergraduate Student of Management, Perm State National Research University, e-mail: marketing.psu@yandex.ru. 